\title{
Phase Transformations in Two C-Mn-Si-Cr Dual Phase Steels
}

\author{
A. MURUGAIYAN, A. SAHA PODDER, ${ }^{*}$ A. PANDIT, S. CHANDRA, D. BHATTACHARJEE and R. K. RAY \\ R\&D and Scientific Services Division, Tata Steel, Jamshedpur-831 001, India.* E-mail: arijit.sahapodder@tatasteel.com
}

(Received on April 11, 2006; accepted on August 1, 2006)

\begin{abstract}
The continuous cooling transformation behaviour of dual phase steels were studied with emphasis on the effects of addition of chromium, cooling rate and intercritical annealing temperature on the volume fractions of different transformed products of austenite. The results show that addition of $0.21 \%$ chromium promotes the formation of acicular products in the final microstructure and does not have much effect on the volume fractions of the co-existing phases at intercritical annealing temperatures. A mathematical model based on Avrami's equation and Scheil's additivity principle was developed to predict the volume fractions of polygonal ferrite as a function of cooling rate for one of the continuous cooled steels. The predicted results from the model show good agreement with experimental observations.
\end{abstract}

KEY WORDS: dual phase steel; phase transformation kinetics; substitutional diffusion; microstructural map.

\section{Introduction}

Conventional dual phase steels are a class of high strength steels (HSS) that are characterized by a microstructure typically consisting of a dispersion of about 20 to $30 \%$ of a hard phase in a soft ferritic matrix. The dispersed hard phase could be either martensite or bainite. The ferrite-martensite dual phase steels are characterised by a continuous yielding behaviour, a high value of the strain hardening exponent $n$, excellent elongation and a much higher ultimate tensile strength of formed components vis$\grave{a}$-vis conventional HSS steels of similar strength. As a result of these attractive properties these steels are being very actively considered for weight-saving applications in automobiles. ${ }^{1-4)}$ For commercial exploitation of these steels, it is necessary to thoroughly understand their phase transformation behaviour with emphasis on their chemical composition and response to inter-critical annealing and continuous cooling treatments. In fact, industrially it will be very useful to know precisely the quantitative distribution of the different phases present in these steels as a function of the above mentioned parameters. It is being increasingly realised that many of the commercial dual phase steel compositions in the eighties and the nineties which were considered as made up of ferrite and martensite only, may not be that simple really and may instead consist of more than just two phases. For precise prediction of the properties of such steels it is therefore essential to fully characterise their phase distribution in a quantitative manner.

In the present work, a detailed study on the phase transformation behaviour of two dual phase steel compositions as a function of the rate of cooling from intercritical as well as the fully austenitic region have been carried out and the volume fractions of the different phases formed have been quantitatively evaluated. Microstructural maps have been generated from these data in order to show the nature of variation of volume fractions of different phases under different cooling conditions. A mathematical model based on Avrami's equation ${ }^{5)}$ and at the same time using Scheil's additivity $^{6)}$ principle has been developed to predict the volume fraction of ferrite that can form under continuous cooling transformation conditions.

\section{Experimental Procedure}

Two commercial dual phase steel compositions, one plain $\mathrm{C}-\mathrm{Mn}-\mathrm{Si}$ (Steel 1) and the other C-Mn-Si-Cr (Steel 2) were selected and the alloys were melted in an air induction furnace in the form of $40 \mathrm{~kg}$ ingots. The final compositions of the two steels are given in Table 1. These ingots were hot forged at $1000^{\circ} \mathrm{C}$ to the size $(70 \times 150 \times 400 \mathrm{~mm})$ suitable for further hot-rolling. Hot rolling was carried out in a laboratory scale rolling mill. In the first roughing finish, the ingot thickness was reduced to $25 \mathrm{~mm}$ from $70 \mathrm{~mm}$ in 5 passes. The final finishing was done to further reduce the thickness to $4 \mathrm{~mm}$ in 6 passes. The finish rolling temperature was kept at $850^{\circ} \mathrm{C}$. The samples for continuous cooling transformation (CCT) measurements were prepared from the hot rolled plates. The CCT experiments were carried out in a Gleeble-1500 thermo-mechanical simulator. Tubular steel specimens, with outer diameter of $3 \mathrm{~mm}$ and length of $50 \mathrm{~mm}$ and having wall thickness of $0.7 \mathrm{~mm}$, were used to enable the Gleeble to suppress the recalescence and maintain the required cooling rate throughout the experiment. To study the continuous cooling transformation behaviour, samples were heated to $900^{\circ} \mathrm{C}$ for $15 \mathrm{~min}$ and

Table 1. Composition of steels used in the study (in $\mathrm{wt} \%)$.

\begin{tabular}{|c|c|c|c|c|c|c|}
\hline Steel & $\mathrm{C}$ & $\mathrm{Mn}$ & $\mathrm{Si}$ & $\mathrm{Cr}$ & $\mathrm{S}$ & $\mathrm{P}$ \\
\hline 1 & 0.19 & 1.5 & 0.47 & 0.057 & 0.012 & 0.017 \\
2 & 0.20 & 1.56 & 0.42 & 0.21 & 0.012 & 0.016 \\
\hline
\end{tabular}


cooled at various cooling rates such as $0.1,1,5,10,30,50$ and $100{ }^{\circ} \mathrm{C} / \mathrm{s}$. The start and end of transformations at each cooling rate were found out by dilatometric observations. To study the effect of intercritical annealing temperature on the volume fraction of phases, samples were heated to temperatures within the intercritical $\alpha+\gamma$ region such as 700 , 750 and $800^{\circ} \mathrm{C}$ and soaked for $15 \mathrm{~min}$, then cooled in air and water. Quantitative metallographic studies were carried out using an optical microscope with Leica-QV Image analyzer software to determine the volume fractions of different phases that were formed after the treatment. Etchants such as $5 \%$ Nital, and LaPera solution (4\% Picral and $1 \%$ Sodium Metabisulphide) were used to distinguish the phases for quantitative metallographic analysis. A JEOL Scanning Electron Microscope (JEOL-6400) attached with EDS detector was used to study the elemental distribution in the treated samples.

\section{Results and Discussion}

\subsection{Description of Microstructure}

Figures 1 and $\mathbf{2}$ show the scanning electron micrographs of as hot rolled steels 1 and 2. As hot rolled microstructure of steel 1 shows ferritic+pearlitic microstructure whereas steel 2 shows the presence of bainite, in spite of the fact that both the steels were cooled in air after hot rolling from the finish rolling temperature of $850^{\circ} \mathrm{C}$. Due to the higher chromium content of steel 2 as compared to steel 1 , the austenite in the former got more enriched with chromium. The preferential partitioning of chromium in the austenite made the austenite in steel 2 even more enriched with chromium which eventually stabilised the carbides and thereby resulted in the formation of bainite in the final microstructure. This has been confirmed by the EDS analysis of the as hot rolled samples as shown in the above figures.

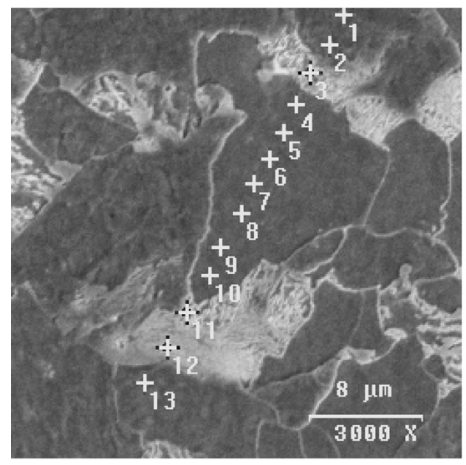

\begin{tabular}{|c|c|c|c|}
\hline Feature & $\begin{array}{c}\mathbf{S i} \\
(\mathbf{K} \boldsymbol{\alpha})\end{array}$ & $\begin{array}{c}\mathbf{C r} \\
(\mathbf{K} \boldsymbol{\alpha})\end{array}$ & $\begin{array}{c}\mathbf{M n} \\
(\mathbf{K} \boldsymbol{\alpha})\end{array}$ \\
\hline 1 & 0.23 & 0.00 & 1.55 \\
\hline 2 & 0.43 & 0.00 & 1.77 \\
\hline 3 & 0.22 & 0.16 & 2.07 \\
\hline 4 & 0.36 & 0.00 & 1.50 \\
\hline 5 & 0.39 & 0.00 & 1.50 \\
\hline 6 & 0.47 & 0.00 & 1.56 \\
\hline 7 & 0.43 & 0.00 & 1.64 \\
\hline 8 & 0.40 & 0.00 & 1.62 \\
\hline 9 & 0.29 & 0.00 & 1.55 \\
\hline 10 & 0.39 & 0.00 & 1.70 \\
\hline 11 & 0.42 & 0.13 & 1.99 \\
\hline 12 & 0.34 & 0.17 & 1.90 \\
\hline 13 & 0.39 & 0.00 & 1.62 \\
\hline
\end{tabular}

Fig. 1. Alloying elements distribution in as hot rolled steel 1.

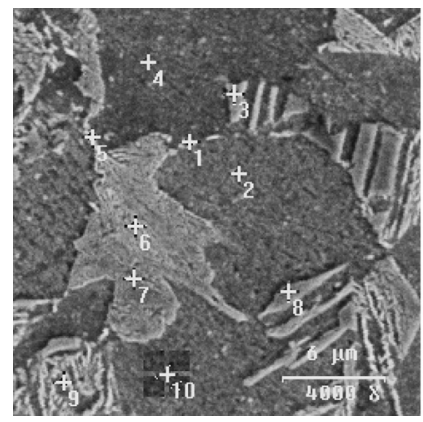

\begin{tabular}{|c|c|c|c|}
\hline Feature & $\mathbf{S i}(\mathbf{K} \boldsymbol{\alpha})$ & $\mathbf{C r}(\mathbf{K} \boldsymbol{\alpha})$ & $\mathbf{M n}(\mathbf{K} \boldsymbol{\alpha})$ \\
\hline 1 & 0.53 & 0.40 & 1.85 \\
\hline 2 & 0.22 & 0.23 & 1.67 \\
\hline 3 & 0.39 & 0.42 & 1.91 \\
\hline 4 & 0.40 & 0.26 & 1.78 \\
\hline 5 & 0.37 & 0.27 & 1.88 \\
\hline 6 & 0.37 & 0.39 & 2.04 \\
\hline 7 & 0.28 & 0.30 & 1.71 \\
\hline 8 & 0.38 & 0.27 & 1.74 \\
\hline 9 & 0.29 & 0.39 & 1.66 \\
\hline 10 & 0.34 & 0.14 & 1.74 \\
\hline
\end{tabular}

Fig. 2. Alloying elements distribution in as hot rolled steel 2.
It appears that chromium partitioning takes place in both the steels but the amount of chromium in the second phase of steel 1 is very low compared with that in steel 2 due to the fact that steel 2 had more chromium in the bulk composition. Though the bulk chromium in steel 2 is only 0.21 $\mathrm{wt} \%$, the amount of chromium in the second phase of steel 2 went as high as $0.50 \mathrm{wt} \%$. In addition to chromium, manganese also partitioned into austenite formed during rolling. The presence of higher amount of chromium in steel 2 may ultimately result in the formation of acicular bainitic products even during air cooling. An earlier paper by Aaronson and Domian ${ }^{7)}$ postulated that $\mathrm{Cr}$ is hardly partitioned during ferrite transformation. However, later work by Ridley ${ }^{8)}$ and by Williams et al. $^{9)}$ has shown that partitioning can take place in the $\mathrm{Fe}-\mathrm{Mn}-\mathrm{C}$ and $\mathrm{Fe}-\mathrm{Cr}-\mathrm{C}$ systems at temperatures as low as $550^{\circ} \mathrm{C}$.

The continuous cooling transformation of austenite from $900^{\circ} \mathrm{C}$ at different cooling rates shows that even at the slowest possible cooling rate of $0.1^{\circ} \mathrm{C} / \mathrm{s}$, while steel 1 (Fig. 3) showed quite a large volume of pearlite, hardly any resolved pearlite could be observed in case of steel 2 (Fig. 4), which showed presence of bainite instead. This clearly indicates that formation of a bainitic structure is quite possible in steel 2 simply by air cooling which involves a cooling rate that is several times higher than $0.1^{\circ} \mathrm{C} / \mathrm{s}$, as used in the present experiment.

The volume fraction of polygonal ferrite decreased while

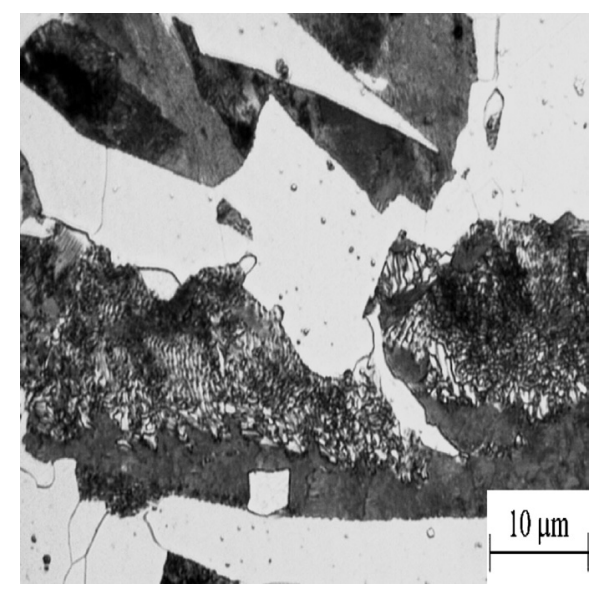

Fig. 3. Microstructure of steel 1 , cooled from $900^{\circ} \mathrm{C}$ at $0.1{ }^{\circ} \mathrm{C} / \mathrm{s}$ showing resolved pearlite.

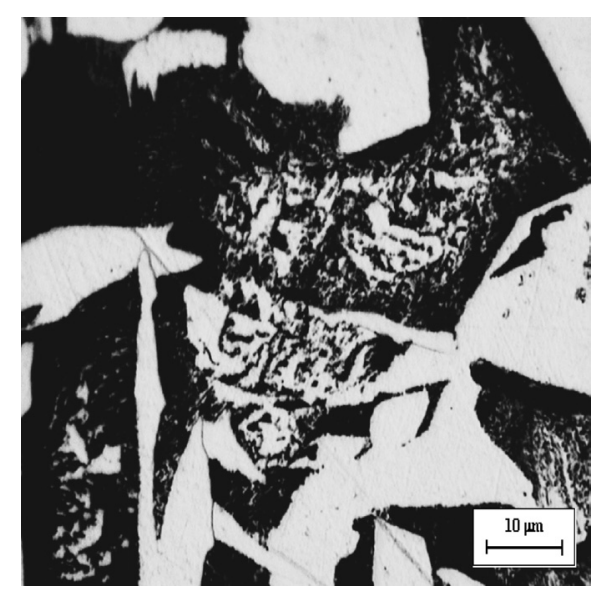

Fig. 4. Microstructure of steel 2 , cooled from $900^{\circ} \mathrm{C}$ at $0.1^{\circ} \mathrm{C} / \mathrm{s}$ showing no resolved pearlite. 


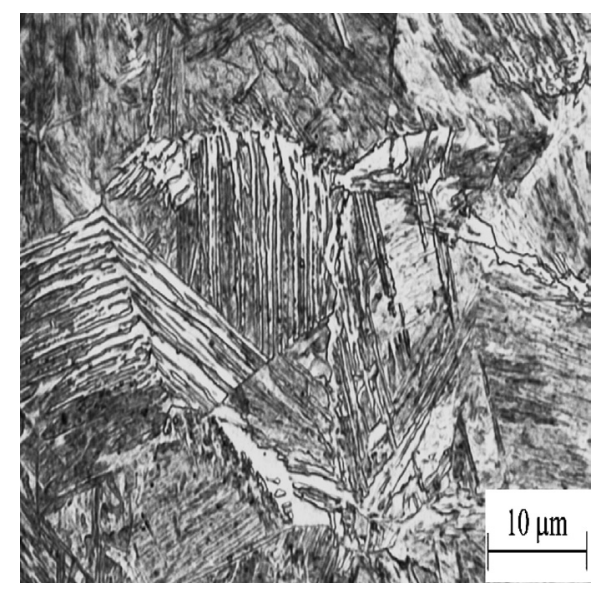

Fig. 5. Microstructure of steel 1 , cooled from $900^{\circ} \mathrm{C}$ at $30^{\circ} \mathrm{C} / \mathrm{s}$, showing acicular products.

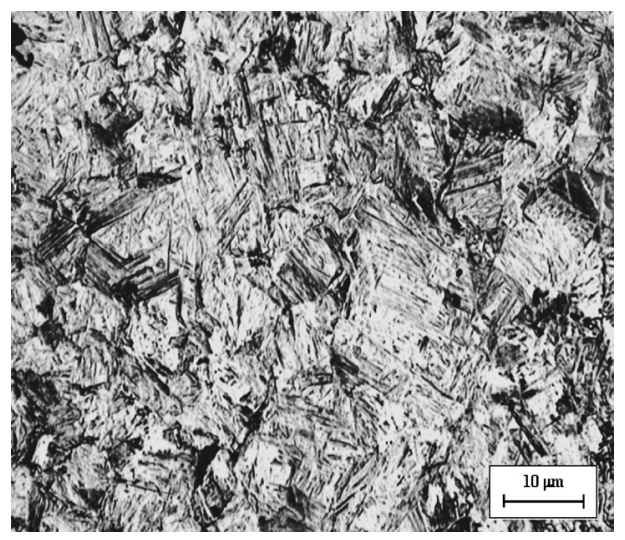

Fig. 6. Microstructure of steel 2 , cooled from $900^{\circ} \mathrm{C}$ at $30^{\circ} \mathrm{C} / \mathrm{s}$, showing martensitic structure.

the amount of "acicular products" increased in both the steels when the cooling rate was increased from $0.1{ }^{\circ} \mathrm{C} / \mathrm{s}$. The term "acicular products" here means essentially the bainitic phase. Sometimes very small amounts of acicular ferrite and/or widmanstatten ferrite were also detected. Separate identification of these small amounts of the latter phases was not attempted due to experimental difficulty and therefore the general term "acicular products" was used instead of using bainite alone. It was evident from the experimental results that the formation of "acicular products" starts much earlier in steel 2 than in steel 1. At the cooling rate of $5^{\circ} \mathrm{C} / \mathrm{s}$, steel 2 did not contain any polygonal ferrite in its microstructure whereas steel 1 had some amount of polygonal ferrite even after cooling at $50^{\circ} \mathrm{C} / \mathrm{s}$. At the cooling rate of $30^{\circ} \mathrm{C} / \mathrm{s}$, the microstructure of steel 1 (Fig. 5) showed the presence of only the acicular products, while an almost fully martensitic structure was obtained in case of steel 2 (Fig. 6). The presence of these phases was confirmed from microhardness results. In fact steel 1 showed very little presence of martensite even after cooling rate of $100^{\circ} \mathrm{C} / \mathrm{s}$. This is mainly due to the presence of lower amounts of alloying elements such as chromium in steel 1 as compared to steel 2. Chromium is known for the ability to increase the hardenability of the austenite by partitioning from the ferrite matrix. All the above microstructural details have been presented in the form of microstructural maps of both the steels (Figs. 7 and 8). These maps show

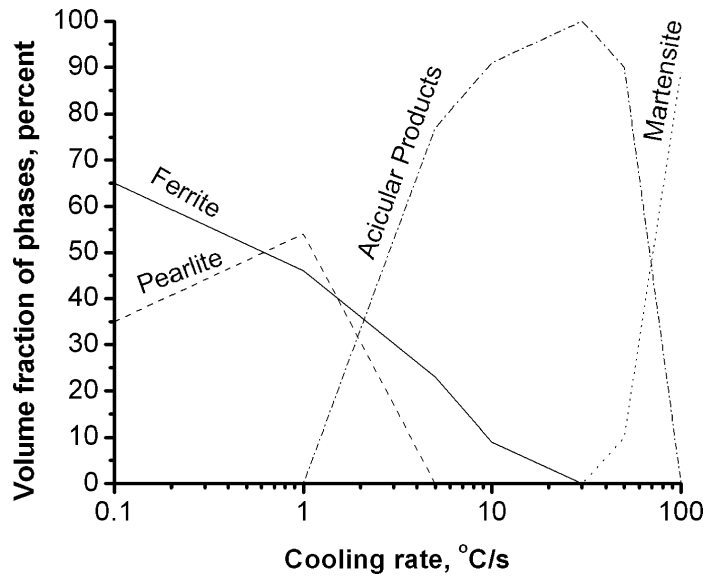

Fig. 7. Microstructure map of steel 1.

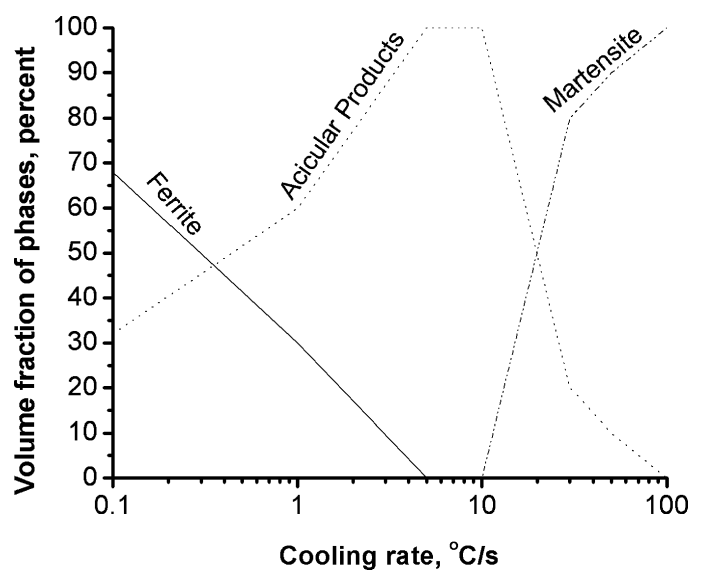

Fig. 8. Microstructure map of steel 2.

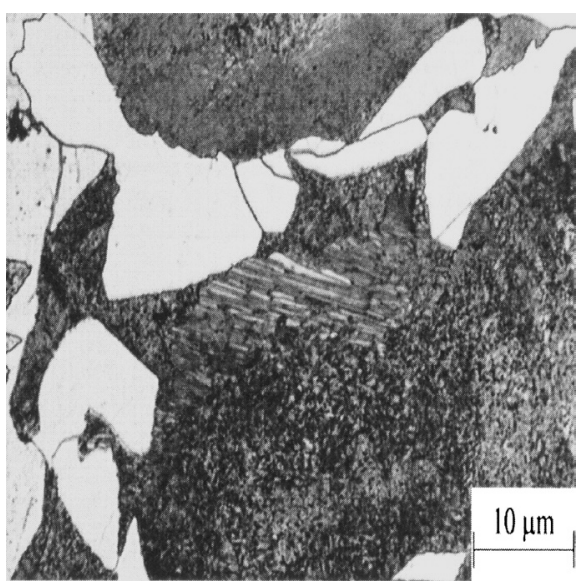

Fig. 9. Microstructure of steel 1 , cooled from $700^{\circ} \mathrm{C}$ in air showing partially resolved pearlite.

the variation of volume fraction of different phases that were obtained under various cooling rates.

The differences in the microstructures of samples of both the steels which were soaked at intercritical annealing temperatures such as 700,750 and $800^{\circ} \mathrm{C}$ followed by cooling in air, were similar to those observed in case of the samples continuously cooled from the austenitic phase at comparable cooling rate . Thus, the microstructure of the intercritically annealed steel 1 showed ferrite and some resolved pearlite (Fig. 9), whereas under the same conditions, steel 2 showed only ferritic + bainitic microstructure (Fig. 10). 


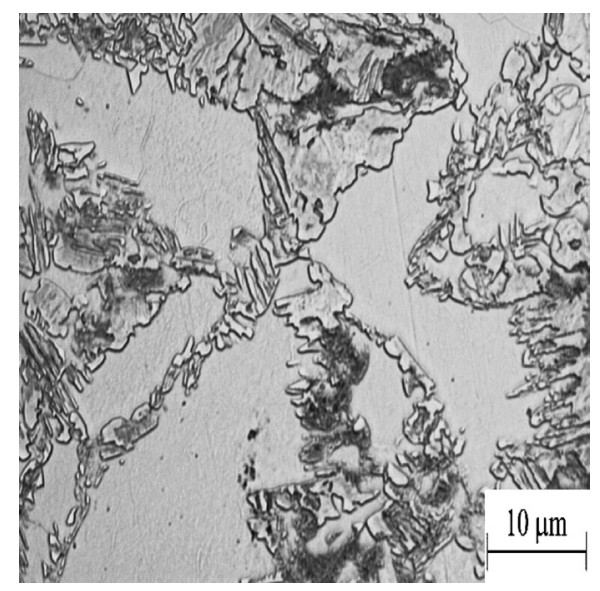

Fig. 10. Microstructure of steel 2, cooled from $700^{\circ} \mathrm{C}$ in air showing ferritic + bainitic structure.

\subsection{Prediction of Phases}

\subsubsection{Background of the Proposed Model}

Prediction of the volume fractions of different phases that can form during continuous cooling transformation needs large number of experiments and sophisticated instrumentation to maintain given cooling conditions. A mathematical model would be a handy tool to predict the volume fraction of phases that can form under practical industrial conditions. In this work an attempt was made to predict the kinetics of austenite to ferrite transformation in multi-phase steels which would be useful to calculate the volume fraction of different phases that are obtainable after continuous cooling. This model requires accurate data on the isothermal phase transformation kinetics of the different steels. These data are then used, in conjunction with the additivity principle, ${ }^{6)}$ to predict continuous cooling transformation kinetics from the isothermal-transformation data, as described by the Johnson-Mehl-Avrami-Kolmogorov (JMAK) theory. ${ }^{10)}$ In the JMAK type equation, the fraction transformed is given by:

$$
X=1-e^{\left(-b t^{n}\right)}
$$

where, $X$ is the volume fraction transformed after time ' $t$ ', ' $b$ ' is a temperature dependant growth constant and ' $n$ ' is the Avrami exponent. Earlier Hawbolt et al. ${ }^{11,12)}$ had developed a mathematical model to predict the continuous cooling transformation kinetics of austenite to ferrite and austenite to pearlite in eutectoid steels. They determined the Avrami constants, $n$ and $b$ from their own experiments in both the transformations. They have also calculated the equilibrium volume fraction of ferrite transformed from the $\mathrm{Fe}-\mathrm{Fe}_{3} \mathrm{C}$ equilibrium diagram, by extrapolating the $\mathrm{A}_{\mathrm{cm}}$ and $\mathrm{A}_{3}$ lines, assuming that these are straight lines. While an attempt was made to apply Hawbolt et al.'s model to predict the experimental volume fraction of ferrite in the present investigation, wide variation between the experimental and predicted values was observed. In fact, using their proposed value of $b$ when we recalculated the predicted volume fractions of ferrite as per their model, these were not found to give a good fit with their experimental data either. ${ }^{11,12)} \mathrm{We}$, therefore, decided to relook into the basic equation, Eq. (1) and concentrated on the two Avrami constants $n$ and $b$. Instead of using Hawbolt et al.'s experimental value of $b$, we calculated the value of this exponent using the empirical relationship suggested by Donney et al. ${ }^{13)}$ because of the versatility of this relationship. In fact, in order to calculate $b$, the latter authors have taken into account the important variables such as composition, austenite grain size and the equilibrium transformation temperatures which we consider to be highly relevant. Again, the equilibrium volume fractions of austenite at different temperatures were calculated, in the present case, by using ThermoCalc ${ }^{\mathrm{TM}}$ instead of by extrapolating the phase boundaries of the $\mathrm{Fe}-\mathrm{Fe}_{3} \mathrm{C}$ equilibrium diagram as was done by Hawbolt et al. ${ }^{11,12)}$ and Agarwal et al. ${ }^{17)}$ Although both the methods are based on equilibrium conditions, which are strictly not correct in the present case, the former method was used in which the effects of other alloying elements on the distribution of carbon could also be taken into account to some extent.

\subsubsection{Formulation of the Proposed Model}

The general theory of transformation kinetics is largely confined to isothermal transformations, but there have been several attempts to predict the course of non-isothermal transformation curves from experimentally determined set of isothermal transformation curves. ${ }^{11-15)}$ From these experimental isothermal transformation curves, the constants in Eq. (1) can be evaluated. This equation also serves as a basis for non-isothermal continuous cooling transformations through the rule of additivity which was first presented by Avrami ${ }^{5)}$ and subsequently extended by Scheil ${ }^{6)}$ and Cahn. ${ }^{16)}$ According to the principle of additivity, the total time to reach a given stage of transformation can be obtained by adding the fractions of the time required to reach the stage in isothermal increments until the sum becomes unity, i.e.,

$$
\int_{0}^{t_{x}} \frac{d t}{t_{\text {iso }}}=1
$$

where $t_{\text {iso }}$ is the time required for fraction $X_{\text {iso }}$ to be transformed isothermally. Agarwal et al. ${ }^{17)}$ report that these conditions are satisfied when the constant " $n$ " in the Eq. (1) is constant throughout the transformation and " $b$ " in their equation only depends on the temperature of transformation.

\subsubsection{Variation of Avrami's Growth Constant " $b$ " with Temperature}

To calculate the isothermal kinetics of ferritic transformation, the growth constant " $b$ " is calculated at any temperature, $T$. The $b$ value must vary in function of the temperature in a way linked to the form of a TTT diagram. To describe accurately the temperature dependence of $b$, the formalism of the function $b=f(T)$ must be carefully chosen. Donnay et al. ${ }^{13)}$ have suggested that modified Gaussian function is adequate:

$$
b=k_{1}\left[\exp \left(-\left(\frac{T-k_{2}}{k_{3}}\right)^{k_{4}}\right)\right]
$$




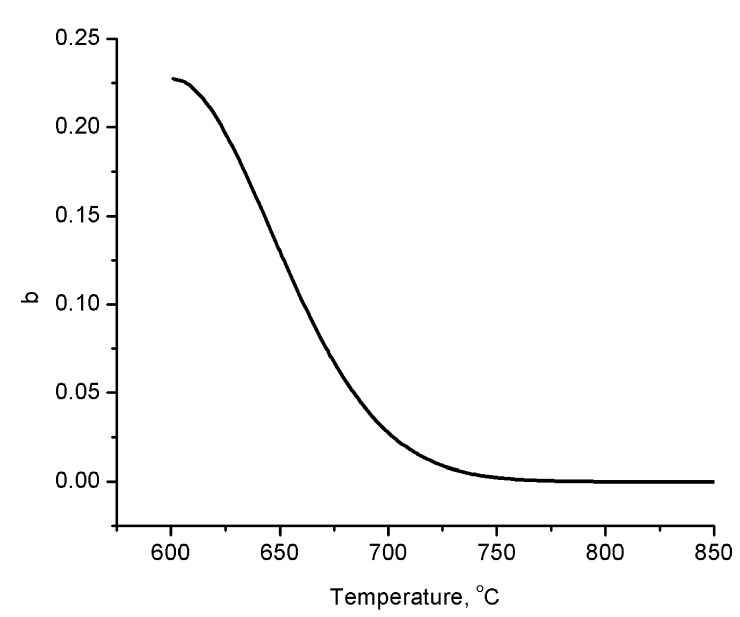

Fig. 11. Variation of " $b$ " with temperature.

Figure 11 shows such a modified Gaussian function. The four parameters of Eq. (3) allow the description of all shapes of TTT curve in a quite intuitive way: in fact (see Fig. 11), $k_{1}$ is the maximum value of $b, k_{2}$ is the temperature position of nose, $k_{3}$ is proportional to the nose width thickness at mid height and $k_{4}$ is related to the sharpness of the curve.

Here,

1. $k_{1}=2 /\left(D_{\text {aus }} \cdot(C+(M n / 6))\right), D_{\text {aus }}$ is the prior austenite grain diameter, which has been experimentally found out as $20 \mu \mathrm{m}$ and $C, M n$ are weight percentage of carbon and manganese in the bulk composition of steel 1 .

2. $k_{2}=A_{\mathrm{c} 3}-210+\left(400 / D_{\text {aus }}\right)-170 C$,

3. $k_{3}=76$ and

4. $k_{4}=1.9$

The predicted " $b$ " values for the composition selected in this study shows a gaussian variation with respect to temperature as shown in Fig. 11. The value of $b$ reaches maximum at the nose temperature of TTT curves where the activation energy for the transformation is minimum. ${ }^{10)}$ For austenite to ferrite transformation the value of exponent " $n$ " in equation 1 is considered to be 1.5 for diffusion controlled growth of all shapes of particles growing from small dimensions with decreasing nucleation rate. ${ }^{10,13)}$

\subsubsection{Prediction of Continuous Cooling Transformation from Isothermal Data}

To predict the kinetics of transformation during continuous cooling, the continuous cooling path is divided into small isothermal time segments with interval of $\Delta t$. The fraction of austenite transformed is calculated assuming additive isothermal time segments. The calculation of fraction of ferrite formed is initiated at ' $t_{0}$ ' and proceeds as shown in Fig. 12.

In the first time segment $\Delta t$ at temperature $T_{0}$, the fraction of ferrite $X_{0}$ formed is calculated as follows,

$$
X_{0}=1-\exp \left[-b\left(T_{0}\right) \Delta t^{1.5}\right]
$$

After time $\Delta t$, the temperature is reduced to $T_{1}\left(T_{0}-\Delta T\right)$, and therefore in order to calculate the actual fraction of ferrite formed during this cooling, the time required for the formation of $X_{0}$ amount ferrite will be,

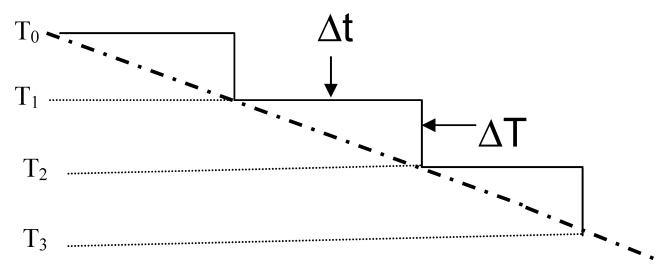

Fig. 12. Discretizaion of continuous cooling into small isothermal time steps of $\Delta t$.

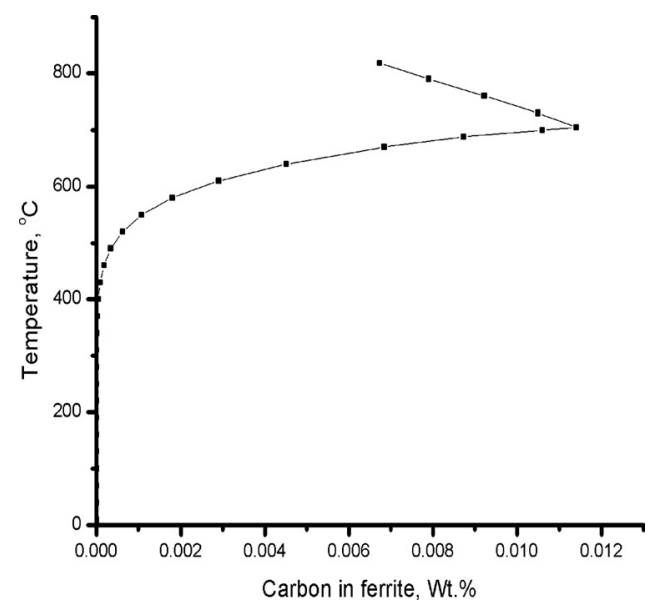

Fig. 13. Variation of carbon in ferrite for steel 1.

$$
\Phi=\left[\frac{\ln \left[1 /\left(1-X_{0}\right)\right]}{b\left(T_{1}\right)}\right]^{1 / 1.5}
$$

The total fraction of ferrite formed $X_{\mathrm{F}}$ during continuous cooling from $T_{0}$ to $T_{1}$ will be

$$
X_{\mathrm{F}}=1-\exp \left[-b\left(T_{1}\right)(\Delta t+\Phi)^{1.5}\right]
$$

This value of $X_{\mathrm{F}}$ is then corrected to the fraction of austenite transformed $X_{\mathrm{T}}$ during cooling from $T_{0}$ to $T_{1}$ by

$$
X_{\mathrm{T}}=X_{\mathrm{F}} \cdot X_{\mathrm{eq}}
$$

Where,

$$
X_{\mathrm{eq}}=\left[\frac{c-c_{\gamma}}{c_{\alpha}-c_{\gamma}}\right]
$$

This procedure is repeated at every time interval and the total fraction of austenite transformed is calculated by summing up the $X_{\mathrm{T}}$ values until the carbon in untransformed austenite becomes more than the equilibrium carbon level (Extended $\mathrm{A}_{\mathrm{cm}}$ ).

Figures 13 and 14 show the calculated variation of carbon in ferrite $c_{\alpha}$ and in austenite $c_{\gamma}$ with temperature for steel 1. These data were obtained from ThermoCalc(TN). The effect of other alloying elements on the distribution of carbon has also been taken into account. These data are then fitted into Eq. 8 in order to determine the equilibrium volume fractions of ferrite as a function of temperature. Figure 15 shows the comparison between experimental and predicted volume fractions of ferrite as a function of cooling rate in the case of steel 1 . This figure shows that the 


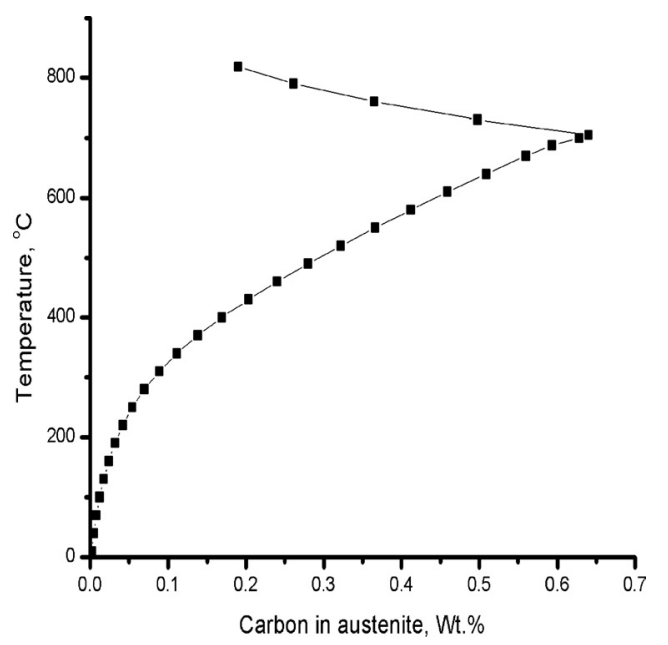

Fig. 14. Variation of carbon in austenite for steel 1.

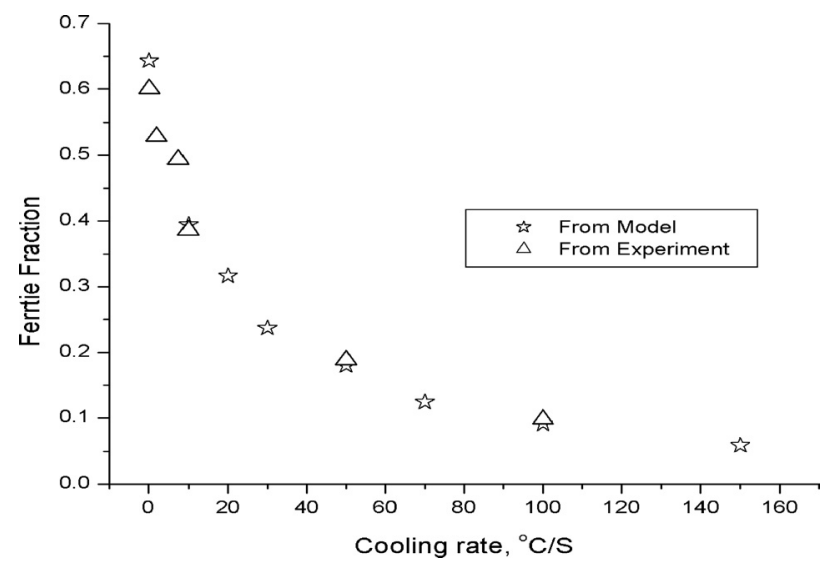

Fig. 15. Comparison between the predicted and the experimental volume fraction of ferrite.

predicted volume fraction matches with the experimental result satisfactorily. The effect of cooling rate on the start and finish temperatures, as per experiments and the model, is shown in Fig. 16. This also demonstrates excellent matching of the experimental data with data obtained from the model.

The above exercise amply demonstrates that by using the JMAK theory, incorporating realistic values of the Avrami exponents $n$ and $b$, and the principle of additivity, it is possible to formulate a simple model to predict the experimental volume fractions of ferrite as a function of cooling rate in one of the experimental steels. This exercise is now being carried out for other steel compositions as well.

\section{Conclusions}

(1) The presence of chromium increases the hardenability of austenite during intercritical annealing and continuous cooling by its partitioning into the austenite phase. This promotes the formation of acicular products such as bainite.

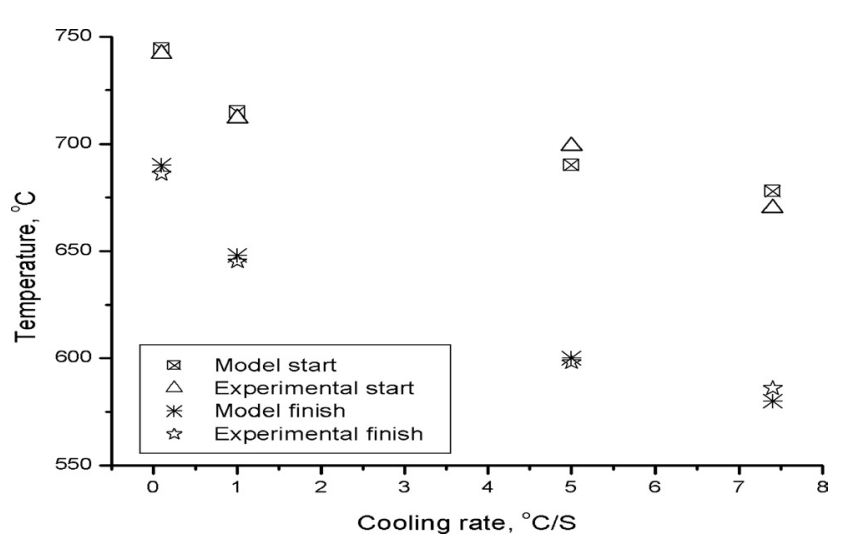

Fig. 16. Comparison between the predicted and the experimental start and finish temperature of ferrite transformation.

(2) Chromium addition in the order of $0.2 \mathrm{wt} \%$ does not affect the relative volume fraction of the co-existing austenite and ferrite phases at intercritical annealing temperature.

(3) A model based on Avrami's equation and Scheil's additivity principle can very well predict the kinetics of austenite to ferrite transformations in multiphase steels.

\section{Acknowledgement}

The authors wish to thank the management of Tata Steel, Jamshedpur, India for allowing this work to be published.

\section{REFERENCES}

1) G. R. Speich: Fundamentals of Dual Phase Steels, ed. by R. A. Kot and B. L. Bramfitt, AIME, New York (NY), (1981), 3.

2) W. S. Owse: Met. Technol., 7 (1980), 1.

3) S. Hayami and T. Furakawa: Microalloying 75, Session 2A, Vanitec, London, (1975), 78.

4) M. S. Rashid: SAE Preprint 760206, (1976).

5) M. Avrami: J. Chem. Phys., 8 (1940), 212.

6) E. Scheil: Arch. Eisenhüttcnwes., 8 (1935), 565.

7) H. I. Aaronson and H. A. Domian: Trans. Met. Society of AIME, 236 (1966), 781 .

8) N. Ridley: Solid-Solid Phase Transformations, TMS-AIME, Pennsylvania, (1981), 807.

9) P. R. Williams, M. K. Miller and G. D. W. Smith: Solid-Solid Phase Transformations, TMS-AIME, Pennsylvania, (1981), 813.

10) J. W. Christian: The Theory of Transformations in Metals and Alloys, Part 1, Pregomon Press, Oxford, (1975).

11) E. B. Hawbolt, B. Chau and J. K. Brimacombe: Metall. Trans. A, 14A (1983), 1803.

12) E. B. Hawbolt, B. Chau and J. K. Brimacombe: Metall. Trans. A, 16A (1985), 565.

13) B. Donney, J. C. Herman, V. Leroy, U. Lotter, Grossterlinder and H. Pircher: Proc. of 2nd Int. Conf. on Modelling of Metal Rolling Processes, ed. by J. H. Beynon, P. Ingham, H. Teichert and K. Waterson, The Institute of Materials, London (UK), (1996), 23.

14) L. M. Victor, D. V. Niebuhr, L. L. Meekishno and D. G. Atteridge: Metall. Mater. Trans. B, 29B (1998), 661.

15) S. Serajzadeh: Appl. Math. Model., 27 (2003), 861.

16) J. W. Cahn: Acta Metall., 4 (1956), 572.

17) P. K. Agarwal and J. K. Brimacombe: Metall. Trans. B, 12B (1981), 121. 